\title{
MIG WELDING USING 8-AXIS KUKA ROBOT
}

\author{
Sarveh Kishor Talele \\ Department of Mechanical Engineering \\ Centre of Excellence in Maritime and Shipbuilding, Vizag, Andra Pradesh, \\ India
}

\begin{abstract}
From the dawn of modernization, welding plays a very important role in the manufacturing of machines. Welding has made complex structure possible and reached the engineering field at it's best. Welding is a process of joining two or more metals together by melting the adjacent surfaces or by melting it by using a third material which will act as a glue. On the other hand, using labor is very timeconsuming. The batch assembly which is used for assembling a machine where welding is necessary. For example, Car manufacturing, Submarines, Ships, etc. In these following operations, welding is very much crucial. Hence, to increase the manufacturing speed in industries it is more preferable to use Robots instead of manpower. Along with increasing production rate, it will eventually increase profit for the company along with that skilled labor is required for performing and handling Welding Robots. This paper focuses on the application of MIG Welding KUKA Robot in Industries. It will also elaborate on the components used for MIG welding operations, for example, KEMPPI (KempArc Pulse 450), KRC4 Controller, KR16 R2010 Robotic arm for performing welding on machines. The paper will interpret the importance, analysis, and method of production using an 8-axis KUKA MIG Welding Robot.
\end{abstract}

Keywords - Metal Inert Gas Welding (MIG), KUKA MIG WELDING ROBOT, KR16 R2010, KRC4 Controller, Electrode.

\section{INTRODUCTION}

Welding is the process of joining two or more metals together by melting the adjacent surface, or by melting the third material which would act as a glue, acts normally lighter than the riveted or bolted structures, has very high efficiency and furnish rigid joints et. al. 1993 [12]. Welding provides higher tensile strength, shear strength and durability to the structure et. al. 1995 [11]. Welding applications are widely used for constructing bridges, Ships, cars, and huge monumental structures, etc. After understanding the purpose of welding we will classify them based on their working principle. There are two types of welding operations, Fusion Welding and Solid State welding. Fusion welding is a process in which joining of metal is done by supplying heat to the metal's melting point, by means of chemical or electrical energy. It is also summoned as non-pressure welding. For example, MIG welding, TIG welding, Arc welding, etc. et. al. 2000 .[10]

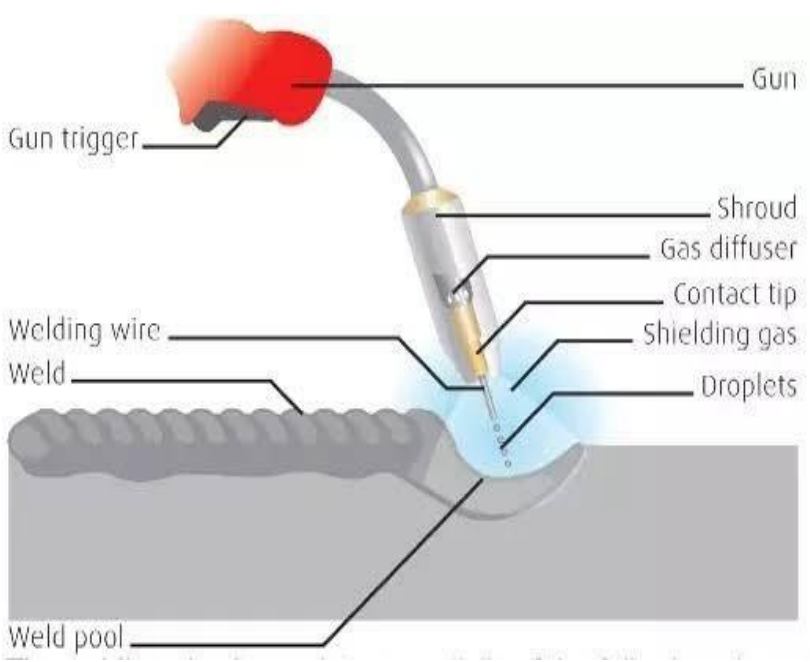

Fig. 1. Fusion Type Welding

Solid State welding is the process in which metal is not melted by any external source but the heat is generated by means of Mechanical (friction) or electrical (resistance). It is also summoned as Pressure welding. For example Friction welding, Electric Resistance welding, etc.

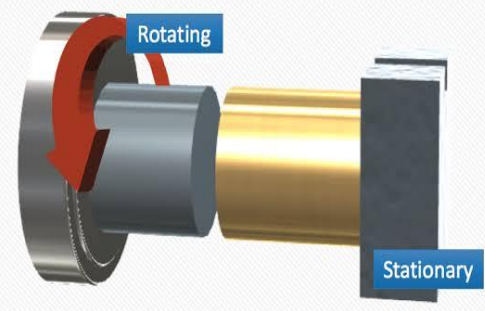

Fig. 2. Solid State Type Welding (Friction Welding) 


\section{International Journal of Engineering Applied Sciences and Technology, 2020 \\ Vol. 4, Issue 10, ISSN No. 2455-2143, Pages 101-105 \\ Published Online February 2020 in IJEAST (http://www.ijeast.com)}

Metal Inert Gas Welding (MIG) is a fusion type welding process, where the joining of metal is achieved by the heat of an electric arc between an electrode and the workpiece[8]. For Kuka Robot MIG Welding, we are using a shielding gas which is composed of the following elements Argon, Helium, Carbon Dioxide, and Oxygen. Shielding gas shields the solidifying molten weld from oxygenation as well as impurities and moisture in the air. This situation may cause corrosiontolerance if the weld, which will affect the accuracy of welding.

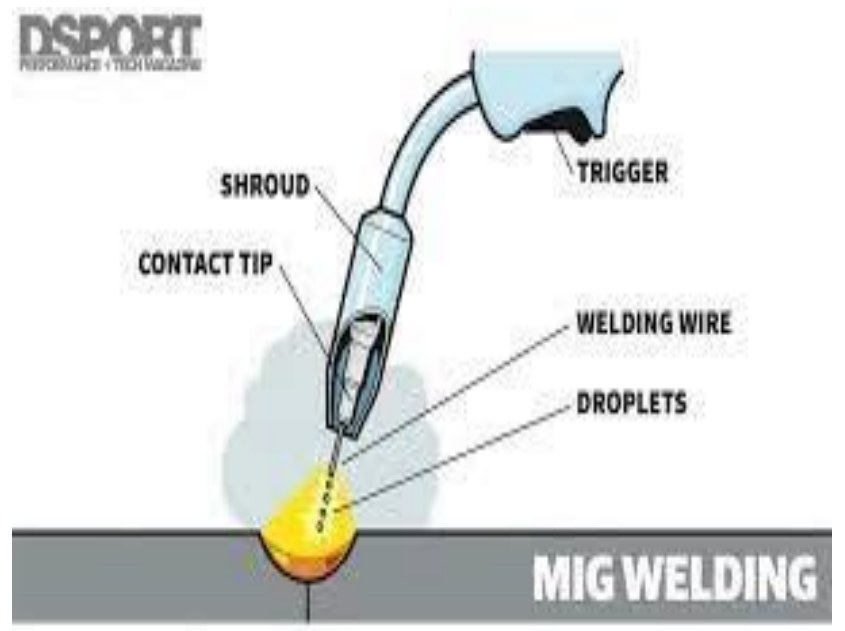

Fig. 3. MIG Welding

The other components which are required for a complete robotic cell are

1. 6 - axis KUKA Robot Arm ( KR16 R2010)

2. KempArc Pulse 450

3. KRC4 controller

4. Wire feeder DT 400L

5. Torch cleaning Tbi BRG-2.

6. Linear track KL250

Every component has a specific purpose to make MIG welding possible. The Robotic cell is an 8-axis MIG welding Kuka Robot, has extra two external linear axes named Linear track KL250. An additional two axes increased production rate and even provided multitasking operations in a single cycle. A detailed description of every component along with its objective is given in the further part of the paper.

\section{SPECIFICATION OF COMPONENTS}

\section{A. 6 - axis KUKA Robot Arm -}

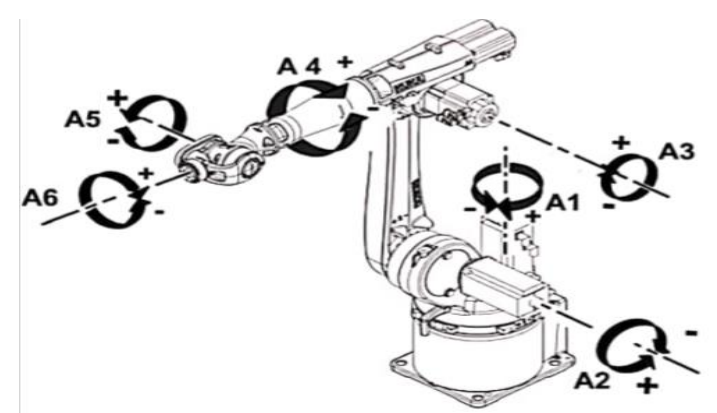

Fig. 4. Kuka Robot

Robotic manipulators are capable of performing repetitive assignments with greater accuracy and precision, which expands the production and manufacturing power of Industries et. al. 1985 [2]. Robots that are operated using servo motors in their joint space, however tasks are defined and objects are manipulated in Cartesian Space.

According to the International Organization for Standardization (ISO), the term robot is defined as an automatically controlled, reprogrammable, multipurpose manipulator that is programmable in three or more axes which can either be fixed in place or mobile for use in Industrial Automation.

The kinematics representation of every robot is classified into two categories namely Forward Kinematics and Inverse Kinematics. Forward Kinematics is defined as the transformation of a robot from joint space coordinate to cartesian space coordinate, i.e., if we know the position of every joint space then the end effector will be at the position respective of joint space et. al 2007 [1]. Inverse Kinematics can be defined as the transformation from Cartesian space to joint space, i.e., where end effector shifts as per the input delivered, the joint space is calculated accordingly by the robot making the end effector fixed as per the requirement.

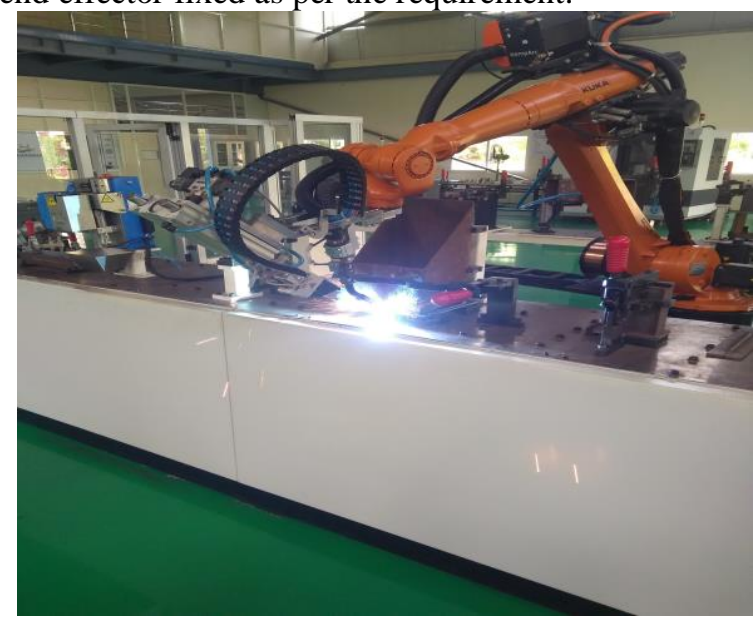

Fig. 5. MIG Welding 8-axis Kuka Robot 


\section{International Journal of Engineering Applied Sciences and Technology, 2020 \\ Vol. 4, Issue 10, ISSN No. 2455-2143, Pages 101-105 \\ Published Online February 2020 in IJEAST (http://www.ijeast.com)}

The KUKA Robot which we are using for welding purposes named KR16 R2010 which is read as Kuka Robot where $16 \mathrm{Kg}$ is the robot payload capacity, the maximum weight that a robot can withstand is defined as payload. R2010 is its Reachability which is $2010 \mathrm{~mm}$. This robot has 6 degrees of freedom which makes the welding process possible more efficiently. The end effector is attached with a welding gun where the shield gas gets heated up to very high temperatures for melting metals. The other two linear axes named as Linear Track KL250 makes welding operation more convenient. These two axes have a rotational motion that is it only has one degree of freedom, the motion is given to those axes to perform multiple operations in a single cycle. The purpose of attaching these two axes is to enhance production rate, reduce manufacturing time for the single workpiece, shielding gas is used appropriately without any wastage of gas.

\section{B. KRC4 Controller -}

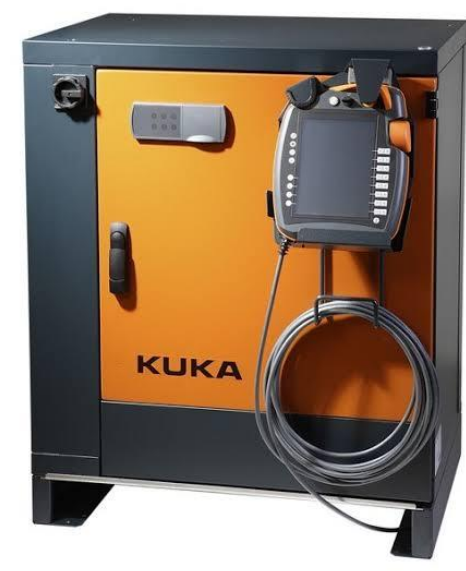

Fig. 6. KRC4 Controller for MIG Welding Robot

The KRC4 Controller is read as Kuka Robot Controller. The main features of this controller are as follows:
1. Control PC (KPC)
2. Drive Power Supply: KUKA Power Pack (KPP)
3. Drive controller: KUKA Servo Pack (KSP)
4. Cabinet Control Unit (CCU)
5. Teach pendant (KUKA SmartPad)
6. Controller System Panel (CSP)
7. Safety Interface Board (SIB)
8. Batteries and Cooling fans, etc.

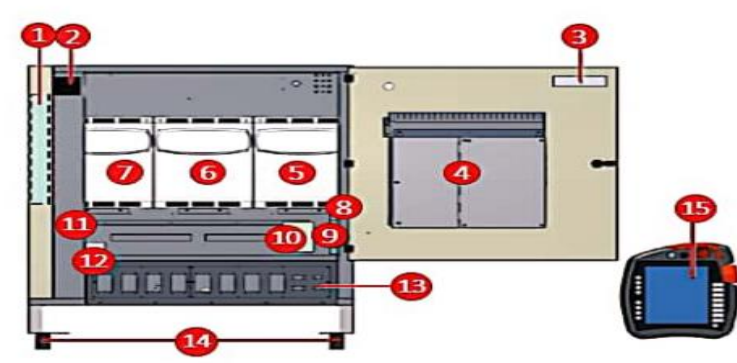

Fig. 7. Components of KRC4 Controller

The component list is as follows:
1. Main filter
2. Main Switch
3. CSP
4. Control PC
5. Drive Power Supply
6. Drive Controller for axes 4 to 6
7. Drive controller for axes 1 to 3
8. Brake Filter
9. $\mathrm{CCU}$
10. SIB
11. Fuse elements
12. Batteries
13. Connection panel
14. Set of rollers
15. KUKA SmartPad

KRC4 Controller is used to programming the Robot for implementing various welding operations on metals.

\section{EXPERIMENT AND RESULT}

Subsequently understanding the fundamentals of KUKA Robot Kinematics and programming, now, focusing on the experiment or say operations performed using MIG welding KUKA Robot [5]. The very first operation is how to clean the torch, it is essential if any impurities in the torch could cause inaccuracies while welding. Hence, for cleaning purposes, Tbi BRG-2 is used. The programming is executed using KUKA SmartPad, based on the inverse kinematics of the robot. 


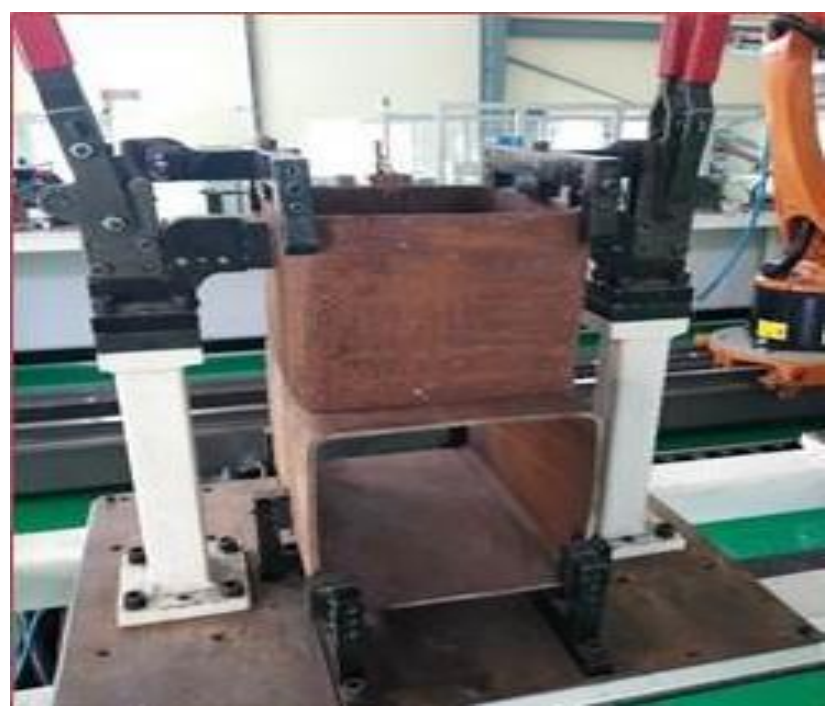

Fig. 8. MIG Welding Operation

Shielding gas is provided using, Wire Feeder DT 400L weighted $4.5 \mathrm{Kg}$ having the rated power of $100 \mathrm{~W}$. The wire feeder is operated at $50 \mathrm{~V} \mathrm{dc}$ voltage. The operating temperature range is from $-20^{\circ} \mathrm{C}$ to $70^{\circ} \mathrm{C}$, wire feeding speed is from 0 to $25 \mathrm{~m} / \mathrm{min}$, the gas contains Argon gas, Helium gas, and Carbon dioxide as well.

Fig 8. shows the operation welding operation performed on the following workpiece, using the MIG welding Robot. But, there are many types of welding patterns which are as follows:

1. Mechanical Weaving

2. Triangle

3. Trapezoid

4. Asymmetrical Trapezoid

5. Spiral

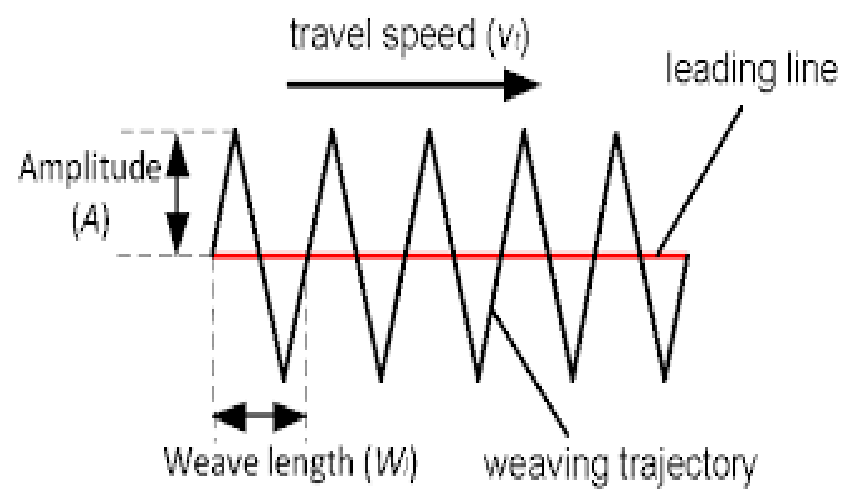

Fig. 9. Mechanical Weaving
These patterns are used to improve the tensile strength of the welded joint[6]. All these patterns are programmed and can be applied to the workpiece using the robot. The most suited pattern for our workpiece is the Spiral welding pattern. Spiral welding can provide better rigidity and shear strength to the workpiece.

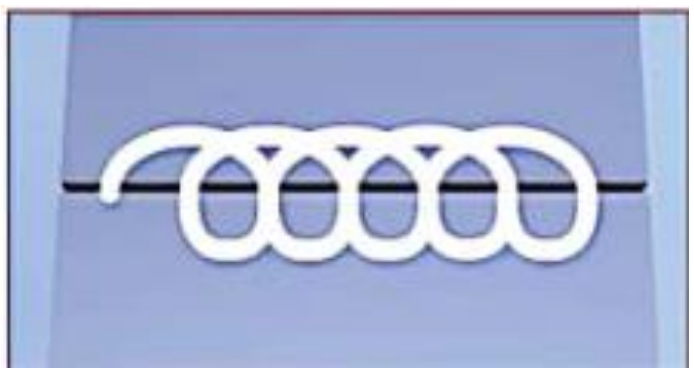

Fig. 10. Spiral Welding pattern

Now, comes the programming section for the robot. The programming language which is being used is KUKA ROBOT LANGUAGE (KRL). The language is available on the smart pad. Smartpad acts as a database for all the programs executed or saved. The robot is being controlled with the help of a smart ad with the help of a 6D mouse or either by buttons provided for different axes. Smartpad operates a robot based on inverse kinematics or forward kinematics as well, based on the user's choice.

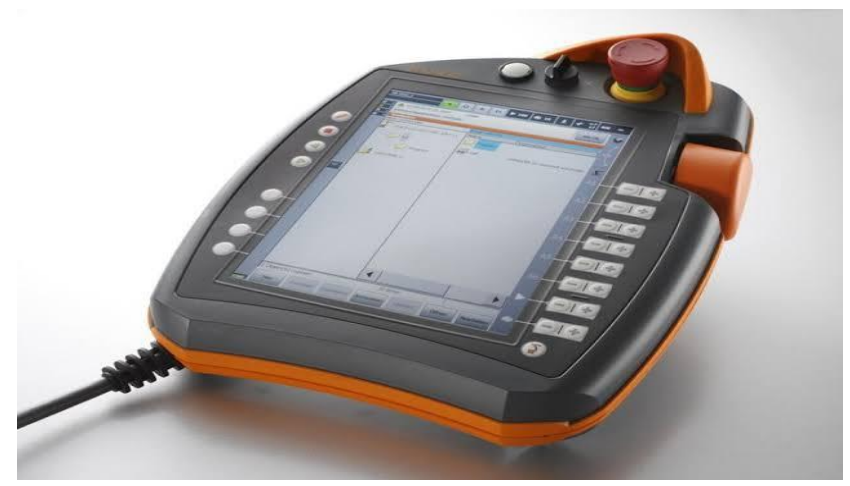

Fig. 11. KUKA SmartPad

Following the instructions, jogging of the robot is performed considering the outer profile of the workpiece as a reference, with a minimum of $2 \mathrm{~mm}$ or a maximum of $3 \mathrm{~mm}$ height. With this amount of height, welding operation can be carried out smoothly without any distortion of melted metal.

Thus, now the welding can be done on the workpiece.

\section{CONCLUSION}

Thus after analyzing and knowing the importance and working of KUKA MIG Welding Robot, we can conclude that using this robot for welding operations with additional two axes will 
eventually increase the production rate and reduce the manufacturing cost, maintenance expenses of the company.

\section{REFERENCE}

1.Koyuncu, B., \& Güzel, M. (2007). Software development for the kinematic analysis of a Lynx 6 robot arm. World Academy of Science, Engineering and Technology, 30, 2007.

2.Shadia Elgazzar, Efficient Kinematic Transformations for the Puma560 Robot September 1985, IEEE Journal of Robotics and automation.

3. Bischoff, R., Kurth, J., Schreiber, G., Koeppe, R., AlbuSchäffer, A., Beyer, A., ... \& Hirzinger, G. (2010, June). The KUKA-DLR Lightweight Robot arm-a new reference platform for robotics research and manufacturing. In ISR 2010 (41st international symposium on robotics) and ROBOTIK 2010 (6th German conference on robotics) (pp. 1-8). VDE.

4.Dahari, M., \& Tan, J. D. (2011, April). Forward and inverse kinematics model for robotic welding process using KR-16KS KUKA robot. In 2011 Fourth International Conference on Modeling, Simulation and Applied Optimization (pp. 1-6). IEEE

5. Brethé, J. F., Vasselin, E., Lefebvre, D., \& Dakyo, B. (2005, April). Determination of the repeatability of a kuka robot using the stochastic ellipsoid approach. In Proceedings of the 2005 IEEE International Conference on Robotics and Automation (pp. 43394344). IEEE.

6. Schreiber, G., Stemmer, A., \& Bischoff, R. (2010, May). The fast research interface for the kuka lightweight robot. In IEEE Workshop on Innovative Robot Control Architectures for Demanding (Research) Applications How to Modify and Enhance Commercial Controllers (ICRA 2010) (pp. 15-21). Citeseer.

7. Ghazvinloo, H. R., Honarbakhsh-Raouf, A., \& Shadfar, N. (2010). Effect of arc voltage, welding current and welding speed on fatigue life, impact energy and bead penetration of AA6061 joints produced by robotic MIG welding. Indian Journal of Science and Technology, 3(2), 156-162.

8. Dahari, M., \& Tan, J. D. (2011, April). Forward and inverse kinematics model for robotic welding process using KR-16KS KUKA robot. In 2011 Fourth International Conference on Modeling, Simulation and Applied Optimization (pp. 1-6). IEEE.

9. Brethé, J. F., Vasselin, E., Lefebvre, D., \& Dakyo, B. (2005, April). Determination of the repeatability of a kuka robot using the stochastic ellipsoid approach. In Proceedings of the 2005 IEEE International Conference on Robotics and Automation (pp. 43394344). IEEE.
10. Yunlian, Q., Ju, D., Quan, H., \& Liying, Z. (2000). Electron beam welding, laser beam welding and gas tungsten arc welding of titanium sheet. Materials Science and Engineering: A, 280(1), 177-181.

11. DuPont, J. N., \& Marder, A. R. (1995). Thermal efficiency of arc welding processes. Welding JournalIncluding Welding Research Supplement, 74(12), 406s.

12. Kim, Y. S., \& Eagar, T. W. (1993). Analysis of metal transfer in gas metal arc welding. WELDING JOURNAL-NEW YORK-, 72, 269-s. 